\title{
Association between MRI Findings and Histopathological Examination in Carcinoma Cervix: A Retrospective Study
}

\section{ABSTRACT}

Introduction: Staging of cervical cancer plays a major role in the treatment and prognosis of the patients. Preoperative Magnetic Resonance Imaging (MRI) is widely reviewed as a method to stage cervical cancer.

Aim: To evaluate the role of MRI in the staging of cervical cancer in correlation with Histopathological Examination (HPE).

Materials and Methods: A retrospective observational hospitalbased study was done on 48 patients with Carcinoma Cervix attending the Velammal Medical College Hospital and Research Institute, Madurai, Tamilnadu. The patients, who had undergone MRI (on 1.5 Tesla Unit) of abdomen and pelvis from June 2018 to July 2019 were included in the study. Tumour location, size, vaginal, parametrial extension, pelvic sidewall involvement, pelvic and retroperitoneal lymphadenopathy, spread to adjacent pelvic organs and distant organs following retroperitoneal lymphadenopathy were reviewed from reports, and histopathology reports were analysed. International Federation of Gynaecology and Obstetrics (FIGO) staging was done for all the cases. HPE findings and $M R I$ findings were assessed for correlation. IBM SPSS version 22.0 was used for statistical analysis. Descriptive analysis was carried out, and values were represented as mean with standard deviation for quantitative variables, frequency and proportion for categorical variables.

Results: The mean age was $54.46 \pm 9.29$ years. The majority $42(87.5 \%)$ of the patients had Squamous cell carcinoma of the cervix on HPE. The majority $23(47.91 \%)$ of the patients had stage IB carcinoma of the cervix. MRI revealed pelvic lymphadenopathy in 04 (8.33\%) of cases, pelvic lymph nodal metastasis was seen in $02(4.16 \%)$ of the HPE cases.

Conclusion: MRI is useful in staging of Carcinoma cervix in stage IB or greater and for planning of treatment. Hence, MRI has the potential to be used as a one-stop-shop diagnostic tool for cervical cancer.

Keywords: Cervical cancer, Correlation, Extension, International federation of gynaecology and obstetrics staging Lymphadenopathy, Magnetic resonance imaging, Vagina

\section{INTRODUCTION}

Malignant (cancer) cells can be formed in the tissues of the cervix, the lower, narrow end of the uterus to result in cervical cancer [1]. Cervical cancer is the fourth most frequent cancer amongst women globally. The burden faced by low and middle-income countries is significantly greater than in high-income countries. The disparity is a direct result of the differences in resources. In developed countries, the new cases and deaths due to cervical cancer have reduced by half compared to thirty years back. This was attributed to the induction of formal screening for cervical cancer [2]. Nearly, all cervical cancers are caused by specific types of Human Papillomavirus (HPV). Prophylactic vaccination for HPV provides the most effective method of primary prevention against HPV-related diseases. The use of the Papanicolaou (Pap) test and HPV test, according to published guidelines, provides the most effective means of screening for cervical cancer [3]

Cancer of the cervix uteri is the second most common cancer (after breast cancer), and the third leading cancer mortality (after lung and breast cancer) among women worldwide [4]. Almost $75 \%$ of all the cervical cancers are squamous cell carcinomas. Other histological variants like adenocarcinoma, adenosquamous cell carcinoma forms the 10-15\% and remaining by other subtypes [5,6]

Histopathological Examination (HPE) of the cervical biopsy remains the most commonly utilised diagnostic tool of cervical cancers [7]. It determines the treatment of cancer and pre-cancer through classifying into diagnosis of the patterns of microscopic organisation of cells in tissue sections from a biopsy or surgical specimens. MRI can be utilised as an efficient imaging tool for the diagnosis and staging of cervical cancer. Lymph node involvements can be assessed. The decision to port site can be made, and follow-up scans can be done to study the treatment impact [8,9]. In 2018, The former International Federation of Gynaecology and Obstetrics (FIGO) revised the 2014 FIGO staging system of cervical cancer. The former FIGO staging system of cervical cancer was mainly based on characteristics of primary tumours and did not take into account the characteristics of positive lymph nodes into consideration while the revised staging system defined patients with regional lymph node metastasis as stage IIIC [10,11].

$\mathrm{MRI}$ is optimal for evaluation of important prognostic factors such as lesion volume and metastatic lymph node involvement. MRI being non-invasive supersedes the use of invasive techniques like cystoscopy and proctoscopy. It is an imperative tool in staging cervical cancer to differentiate early disease (stage IIA) from complex disease (stage IIB or greater). MRI has been in advance use for pretreatment staging of uterine cervical carcinoma; however, it is not yet acknowledged as a Gold Standard [12-15]. The objective of this study was to evaluate the role of MRI in the staging of Carcinoma cervix and to assess the correlation of MRI findings with that of HPE.

\section{MATERIALS AND METHODS}

A retrospective observational hospital-based study was done on 48 patients with Carcinoma Cervix attending the Velammal Medical College Hospital and Research Institute, Madurai, Tamilnadu.

Sample size calculation: The sample size was calculated assuming the proportion of squamous cell carcinomas $73.3 \%$ as per the study by Shweel MA et al., [16]. The other parameters considered for sample size calculation were $13 \%$ absolute precision and a $95 \%$ 
confidence level. An infinite population correction was applied. The following formula was used for sample size calculation [17].

$$
n=\frac{Z^{2} P(1-P)}{d^{2}}
$$

Where, $n=$ Sample size

$Z=Z$ statistic for a level of confidence,

$\mathrm{P}=$ Expected prevalence of proportion (If the expected prevalence was $73.3 \%$, then $\mathrm{P}=0.733$ ), and

$d=$ Precision (If the precision was 13\%, then $d=0.13$ ).

The required number of subjects as per the above mentioned calculation was 45 . To account for a non-participation rate of about $5 \%$ (2 subjects), it was decided to sample about 48 subjects for the study.

The clinical data of all patients diagnosed with carcinoma cervix and who had undergone MRI Study (on 1.5 Tesla Unit) of abdomen and pelvis over a period of 14 months from June 2018 to July 2019 was reviewed. The MRI of our hospital was GE- Optima MR 3601.5 T 16 channel. Standard MRI protocol includes. Pelvis-3 Plane T2, T1 axial, STIR axial, diffusion. Post-contrast-T1FS pre, dynamic contrast for uterus, 3 Plane T1 FS, Axial lava, Coronal lava. Screening of upper abdomen-T2FS Axial, Coronal T2 Haste, diffusion. Contrast agentGadopentetate Dimeglunine Injection USP-10 mL. CompositionGadopentetate Dimeglunine 469 mg in 10 mg. Contrast study was not performed in patients with elevated renal parameters, previous history of contrast allergy and unwillingness for contrast from patient or primary consultant side.

Inclusion criteria: All the patients falling into the sampling frame irrespective of the age, gender, stage of cancer, metastasis or other factors were included in the study since it was only a hospital record-based study.

Exclusion criteria: Patients unable to undergo MRI for any reason were excluded from the study.

The confidentiality of the patient details was maintained throughout the study. The staging was done by 2018 FIGO revised staging system of cervical cancer [11]. HPE findings and MRI findings were assessed.

\section{STATISTICAL ANALYSIS}

All the statistical analysis was done using SPSS version 22.0. Descriptive analysis was carried out, and values were represented as mean with standard deviation for quantitative variables, frequency and proportion for categorical variables.

\section{RESULTS}

A total of 48 subjects were included in the final analysis.

The mean age of the study population was $54.46 \pm 9.29$ years. The youngest patient was 33-year-old, while the oldest was 73-year-old. In HPE, $47.91 \%$ had a mass lesion of the cervix, $16.66 \%$ had with the involvement of upper $2 / 3 \mathrm{rd}$ of the vagina, and $4.16 \%$ had micro-invasive carcinoma cervix and pelvic lymph nodes for each respectively. In MRI, $47.91 \%$ had a mass lesion of cervix confined to the cervix, $16.66 \%$ had an extension to upper two-thirds of the vagina. Approximately, $2 \%$ and $4 \%$ had bladder and rectal invasion, respectively [Table/Fig-1,2].

By FIGO staging of carcinoma cervix, majority of the patients (47.91\%) were stage IB and $16.67 \%$ patients were stage II A and stage II B for each, respectively [Table/Fig-3].

The majority $42(87.5 \%)$ of the patients had squamous cell carcinoma on HPE. Two (4.2\%) participants had poorly differentiated carcinomacervix, while another 2 (4.2\%) had squamous/adenocarcinoma. 1 (2.1\%) participant had adenocarcinomas, and another $1(2.1 \%)$ had carcinoma in situ [Table/Fig-4].

Among the people with chief complaints, majority of 30 (62.5\%) participants had white discharge, followed by postmenopausal bleeding

\begin{tabular}{|c|c|c|}
\hline Involvement/extension & $\begin{array}{l}\text { Frequency } \\
\text { (n) }\end{array}$ & $\begin{array}{c}\text { Percentages } \\
(\%)\end{array}$ \\
\hline \multicolumn{3}{|l|}{ Histopathological Examination (HPE) findings } \\
\hline Mass lesion of the cervix & 23 & 47.91 \\
\hline With the involvement of the upper $2 / 3^{\text {rd }}$ of the vagina & 8 & 16.66 \\
\hline Micro invasive carcinoma cervix & 2 & 4.16 \\
\hline Pelvic lymph nodes & 2 & 4.16 \\
\hline \multicolumn{3}{|l|}{ MRI findings Involvement/Extension } \\
\hline Mass lesion of cervix confined to the cervix & 23 & 47.91 \\
\hline With the extension to upper two-thirds of the vagina & 8 & 16.66 \\
\hline With parametrial infiltration & 8 & 16.66 \\
\hline Pelvic lymphadenopathy & 4 & 8.33 \\
\hline Retroperitoneal lymphadenopathy & 3 & 6.25 \\
\hline With the extension to the lower third of the vagina & 1 & 2.08 \\
\hline Invasion of the urinary bladder & 1 & 2.08 \\
\hline Invasion of rectum & 2 & 4.16 \\
\hline Extension to the pelvic sidewall & 0 & $0 \%$ \\
\hline \multicolumn{3}{|c|}{$\begin{array}{l}\text { [Table/Fig-1]: Descriptive analysis of histopathological and MRI findings involvement/ } \\
\text { extension in the study population* having the common features. } \\
\text { *multiple complaints in same participants; MRI: Magnetic resonance imaging }\end{array}$} \\
\hline
\end{tabular}

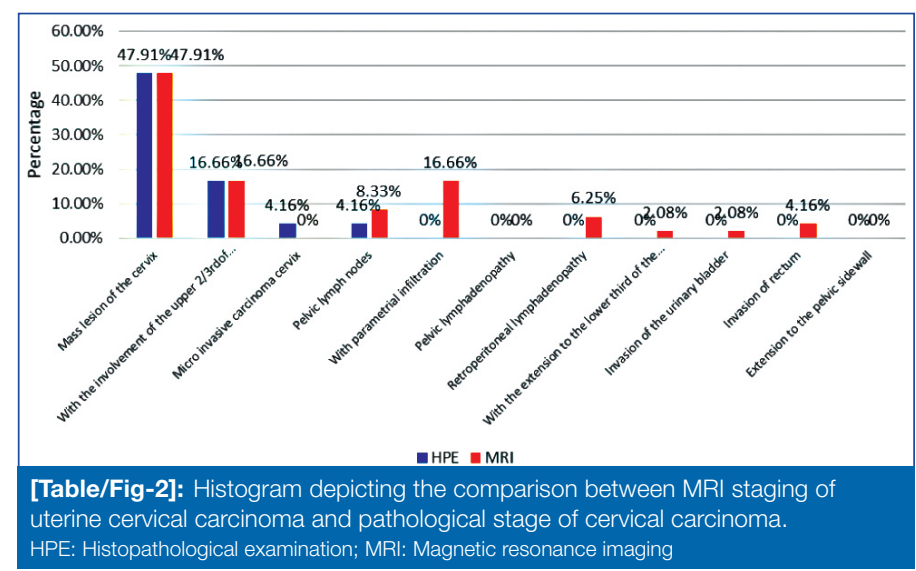

\begin{tabular}{|l|c|}
\hline FIGO staging & Summary N (\%) \\
\hline Stage I B & $23(47.91)$ \\
\hline Stage II A & $8(16.67)$ \\
\hline Stage II B & $8(16.67)$ \\
\hline Stage I A & $2(4.16)$ \\
\hline Stage III C1 & $2(4.16)$ \\
\hline Stage III C2 & $2(4.16)$ \\
\hline Stage IV A & $2(4.16)$ \\
\hline Stage III A & $1(2.08)$ \\
\hline $\begin{array}{l}\text { TTable/Fig-3]: FlGO Staging of carcinoma cenvix in the study population- distribution } \\
\text { of patients (N=48). } \\
\text { FIGO: International federation of gynaecology and obstetrics }\end{array}$ \\
\hline
\end{tabular}

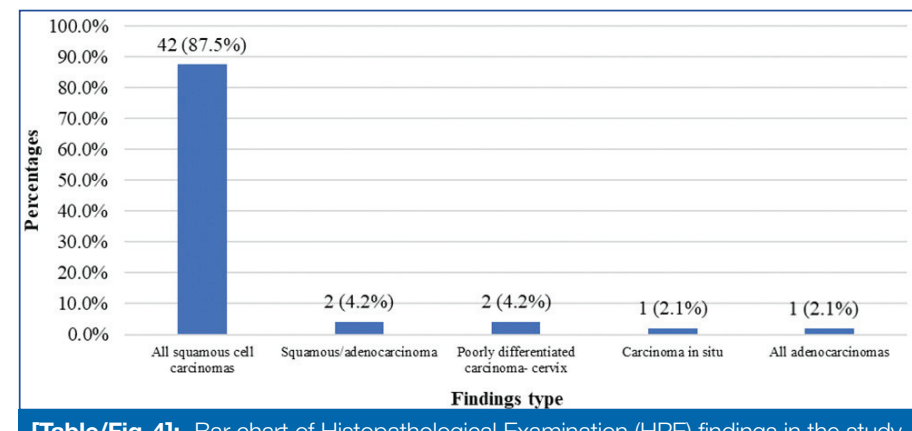

[Table/Fig-4]: Bar chart of Histopathological Examination (HPE) findings in the study population $(\mathrm{N}=48)$.

were 29 (60.4\%), lower abdominal pain was 23 (47.9\%), dysmenorrhea was $8(16.7 \%)$ and other complaints, fatigue and back pain was 6 (12.55\%), 5 (10.4\%) and 4 (8.3\%), respectively [Table/Fig-5]. 


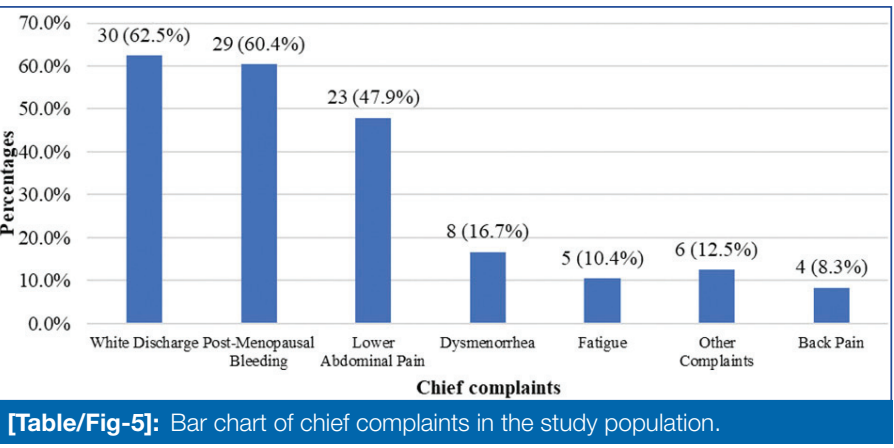

When compared, MRI (mass lesion of the cervix) had a sensitivity of $47.83 \%$ in predicting HPE, specificity was $52 \%$, and the total diagnostic accuracy was $50.00 \%$. When compared, MRI (with the involvement of the upper $2 / 3^{\text {rd }}$ of, the vagina) had sensitivity, specificity, positive predictive value, negative predictive value and the total diagnostic accuracy of $100 \%$ in predicting HPE. When compared, MRI (pelvic lymph nodes) had a sensitivity of $50 \%$ in predicting HPE, specificity was $92.50 \%$, and the total diagnostic accuracy was $90.48 \%$ [Table/Fig-6]. The MRI image showing the cervical cancer lesion has been illustrated in [Table/Fig-7]. findings were compatible with studies conducted by Shweel MA et al., Collettini F and Hamm B, who reported that about $80-90 \%$ of cervical carcinomas were squamous cell carcinoma cases in their study $[16,22]$. The majority $(47.91 \%)$ had stage IB carcinoma of the cervix in our study, while $16.67 \%$ had stage $\| \mathrm{B}$ and another $16.67 \%$ had stage II A carcinoma of the cervix. Shweel MA et al., in their study observed that only $6.6 \%$ had stage IB carcinoma of the cervix, 40.3\% had Stage IIA, 26.6\% had Stage IIB and another $26.6 \%$ had Stage IVA carcinoma [16]. There was a high percentage of stage IB in the present study, as this study being a retrospective study, probably during the given period, there were higher stage IB patients. Two patients have been reported as stage IA in this study. In both the patients, MRI was normal to study and no abnormality was detected.

The correlation between HPE findings and MRI was high in this study. MRI was highly accurate as HPE in detecting the involvement or extension of the carcinoma of the cervix. In both HPE and MRI, $47.91 \%$ had a mass lesion of the cervix, and $16.66 \%$ had with the involvement of upper $2 / 3^{\text {rd }}$ of the vagina. A $4.16 \%$ had metastatic involvement of pelvic lymph nodes on HPE among the $8.33 \%$ of the patientswhohadpelviclymphadenopathydetectedonMRI.Parametrial

\begin{tabular}{|c|c|c|c|c|c|c|c|}
\hline Findings & Sensitivity & Specificity & FPR & FNR & PPV & NPV & Overall diagnostic accuracy \\
\hline Mass lesion of the cervix & $47.83 \%$ & $52 \%$ & $48 \%$ & $52.17 \%$ & $47.83 \%$ & $52 \%$ & $50 \%$ \\
\hline With the involvement of the upper $2 / 3^{\text {rd }}$ of the vagina & $100 \%$ & $100 \%$ & $0 \%$ & $0 \%$ & $100 \%$ & $100 \%$ & $100 \%$ \\
\hline Pelvic lymph nodes & $50 \%$ & $92.50 \%$ & $7.50 \%$ & $50.00 \%$ & $25 \%$ & $97.37 \%$ & $90.48 \%$ \\
\hline
\end{tabular}

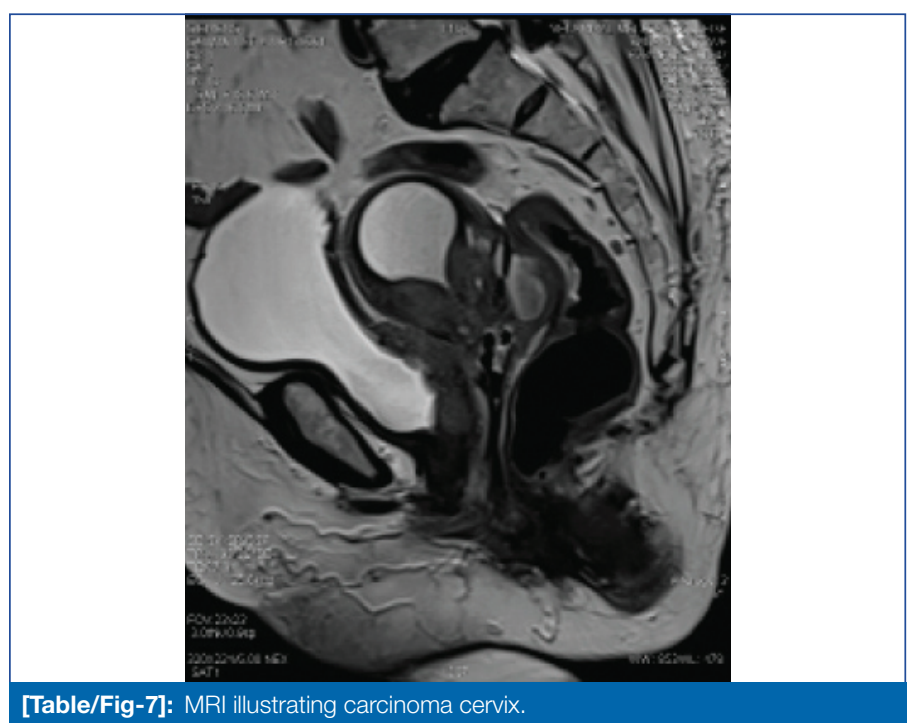

\section{DISCUSSION}

Cervical cancer is the commonest cancer cause of death among women in developing countries [18] in India, the mortality due to cervical cancer is high, and nearly 122,844 new cases are diagnosed, and almost 67,477 deaths occur every year. India, with a high proportion of the population aged 15 years and above, is at risk of developing cervical cancer. Cervical cancer in women aged 15-44 years is the second most common cancer, with the highest standardized mortality rate. Therefore, it is vital to understand the epidemiology of cervical cancer in India [19-21]. Currently, there are two types of diagnostic tests for cervical cancer screening: Papanicolaou test and HPV test. In locally advanced disease, pelvic $\mathrm{MRI}$ and Positron Emission Technology-Computed Tomography (PET-CT) are performed for diagnosis [20]. In the present study, the most common pathological type of the examined cervical mass was squamous cell carcinoma. The majority (87.5\%) had squamous cell carcinoma on HPE while $4.2 \%$ had poorly differentiated carcinoma of the cervix. Only one subject $(2.1 \%)$ had carcinoma in situ. These infiltration, invasion of the rectum, urinary bladder, extension to the lower third of the vagina, retroperitoneal lymphadenopathy were identified by MRI. Magnetic Resonance Imaging staging of cancer cervix was also comparable with histopathologic staging in the study by Shweel MA et al., [16]. Still in their study, MRI over staging was observed in their study on one patient with Stage IIA disease and one patient with Stage IIB disease.

In the study by Shweel MA et al., MRI was highly sensitive (100\%) and specific (100\%) in determining tumour extension to the stroma, urinary bladder, and rectum [16]. Morimura $Y$ et al., in their study also observed that MRI showed very high specificity (99.2\%) and high sensitivity (88.5\%) in detecting cervical stromal invasion [23]. Shweel MA et al., and Rockall AG et al., in their studies have postulated that the absence of bladder or rectal invasion can be diagnosed with sufficient confidence using MRI (NPV=100\%) [16,24]. The low sensitivity of MRI in another study can be due to its inability to identify metastasis in normal-sized lymph nodes [25]. Invasion of the parametrium is an important factor in the evaluation of cancer cervix that significantly influences staging and treatment [26], Shweel MA et al., in their study found the sensitivity of MRI was $100 \%$, with a specificity of $85.7 \%$ in detecting parametrial involvement [16]. In the present study, MRI detected parametrial infiltration in $16.66 \%$ of subjects. Besides being a non-invasive modality, MRI findings in the present study had a high correlation with HPE.

\section{Limitation(s)}

The present study was only a retrospective record-based study with small sample size, only including the subjects falling under our sampling frame. The external validity of our results is poor.

\section{CONCLUSION(S)}

To summarise, $\mathrm{MRI}$ is the imaging modality of choice for the assessment of tumour location, its size, presence of invasion into parametrium, pelvic sidewall or adjacent pelvic organ invasion cases of carcinoma cervix and to determine the treatment strategy which is dependent on the tumour stage. 


\section{Acknowledgement}

We acknowledge the technical support in data entry, analysis and manuscript editing by "Evidencian Research Associates".

\section{REFERENCES}

[1] Pisani P, Parkin DM, Bray F, Ferlay J. Estimates of the worldwide mortality from 25 cancers in 1990. Int J Cancer. 1999;83(1):18-29.

[2] Vu M, Yu J, Awolude OA, Chuang L. Cervical cancer worldwide. Curr Probl Cancer. 2018;42(5):457-65.

[3] Cohen PA, Jhingran A, Oaknin A, Denny L. Cervical cancer. Lancet. 2019;393(10167):169-82.

[4] Kessler TA. Cervical cancer: prevention and early detection. Semin Oncol Nurs. 2017;33(2):172-83.

[5] Parkin DM, Bray FI, Devesa SS. Cancer burden in the year 2000. The global picture. Eur J Cancer. 2001;37 (Suppl 8):S4-66.

[6] Vizcaino AP, Moreno V, Bosch FX, Muñoz N, Barros-Dios XM, Parkin DM. International trends in the incidence of cervical cancer: I. Adenocarcinoma and adenosquamous cell carcinomas. Int J Cancer. 1998;75(4):536-45.

[7] Vizcaino AP, Moreno V, Bosch FX, Muñoz N, Barros-Dios XM, Borras J, et al. International trends in incidence of cervical cancer: II. Squamous-cell carcinoma. Int J Cancer. 2000;86(3):429-35.

[8] Singh N, Arif S. Histopathologic parameters of prognosis in cervical cancer-A review. Int J Gynecol Cancer. 2004;14(5):741-50.

[9] Jenkins D. Histopathology and cytopathology of cervical cancer. Dis Markers. 2007;23(4):199-212.

[10] Mahajan A, Sable NP, Popat PB, Bhargava P, Gangadhar K, Thakur MH, et al. Magnetic resonance imaging of gynecological malignancies: Role in personalized management. Semin Ultrasound CT MR. 2017;38(3):231-68.

[11] Sala E, Rockall AG, Freeman SJ, Mitchell DG, Reinhold C. The added role of MR imaging in treatment stratification of patients with gynecologic malignancies: What the radiologist needs to know. Radiology. 2013;266(3):717-40.

[12] Bhatla N, Aoki D, Sharma DN, Sankaranarayanan R. Cancer of the cervix uteri. Int J Gynaecol Obstet. 2018;143(Suppl 2):22-36.

[13] Liu X, Wang J, Hu K, Zhang F, Meng Q, Wang W, et al. Validation of the 2018 FIGO Staging system of cervical cancer for stage iii patients with a cohort from China. Cancer Manag Res. 2020;12:1405-10. PMID: 32161492.
[14] Okamoto Y, Tanaka YO, Nishida M, Tsunoda H, Yoshikawa H, Itai Y. MR imaging of the uterine cervix: Imaging-pathologic correlation. Radiographics. 2003;23(2):534-35.

[15] Testa AC, Ludovisi M, Manfredi R, Zannoni G, Gui B, Basso D, et al. Transvaginal ultrasonography and magnetic resonance imaging for assessment of presence, size and extent of invasive cervical cancer. Ultrasound Obstet Gynecol. 2009;34(3):335-44.

[16] Shweel MA, Abdel-Gawad EA, Abdelghany HS, Abdel-Rahman AM, Ibrahim EM. Uterine cervical malignancy: Diagnostic accuracy of MRI with histopathologic correlation. J Clin Imaging Sci. 2012;2:42. PMID: 22919556.

[17] Zand KR, Reinhold C, Abe H, Maheshwari S, Mohamed A, Upegui D. Magnetic resonance imaging of the cervix. Cancer Imaging. 2007;7(1):69-76.

[18] Sahdev A, Sohaib S, Wenaden A, Shepherd J, Reznek RJ. The performance of magnetic resonance imaging in early cervical carcinoma: A long-term experience. Int J Gynecol Cancer. 2007;17(3):629-36.

[19] Denny L. Cervical cancer: Prevention and treatment. Discov Med. 2012;14(75):125-31.

[20] Bruni L, Barrionuevo-Rosas L, Albero G, Serrano B, Mena M, Gómez D, et al. ICO information centre on HPV and cancer (HPV information centre). Human papillomavirus and related diseases in the world. Summary Report. 2015;4(08).

[21] Tsikouras P, Zervoudis S, Manav B, Tomara E, latrakis G, Romanidis C, et al Cervical cancer: screening, diagnosis and staging. J buon. 2016;21(2):320-25.

[22] Collettini F, Hamm B. Uterine cervical cancer: Preoperative staging with magnetic resonance imaging.Der Radiologe. 2011;51(7):589-95.

[23] Morimura Y, Soeda S, Hashimoto T, Takano Y, Ohwada M, Yamada H, et al. The value of pre-operative diagnostic procedures for cervical involvement in uterine corpus carcinoma. Fukushima J Med Sci. 2000;46(1-2):01-11.

[24] Rockall AG, Ghosh S, Alexander-Sefre F, Babar S, Younis MT, Naz S, et al. Can MRI rule out bladder and rectal invasion in cervical cancer to help select patients for limited EUA? Gynecol Oncol. 2006;101(2):244-49.

[25] Sala E, Wakely S, Senior E, Lomas D. MRI of malignant neoplasms of the uterine corpus and cervix. AJR Am J Roentgenol. 2007;188(6):1577-87.

[26] Greco A, Mason P, Leung AW, Dische S, Mclndoe GA, Anderson MC. Staging of carcinoma of the uterine cervix: MRI-surgical correlation. Clin Radiol. 1989;40(4):401-05.

PARTICULARS OF CONTRIBUTORS:

1. Associate Professor, Department of Radiodiagnosis, Velammal Medical College Hospital and Research Institute, Madurai, Tamil Nadu, India.

2. Assistant Professor, Department of Radiodiagnosis, Velammal Medical College Hospital and Research Institute, Madurai, Tamil Nadu, India.

NAME, ADDRESS, E-MAIL ID OF THE CORRESPONDING AUTHOR:

Kumaran,

2/586, Alli Street $6^{\text {th }}$ Main Road, Gomathipuram, Madurai, Tamil Nadu, India.

E-mail: rkumaran666@yahoo.co.in

\section{AUTHOR DECLARATION:}

- Financial or Other Competing Interests: None

- Was Ethics Committee Approval obtained for this study? NA

- Was informed consent obtained from the subjects involved in the study? NA

- For any images presented appropriate consent has been obtained from the subjects. NA
PLAGIARISM CHECKING METHODS: [Jain Het al.]

- Plagiarism X-checker: Jul 26, 2020

- Manual Googling: Jan 06, 2021

- iThenticate Software: Feb 22, 2021 (21\%)
ETYMOLOGY: Author Origin

Date of Peer Review: Oct 21, 2020

Date of Acceptance: Jan 06, 2021

Date of Publishing: Apr 01, 2021 